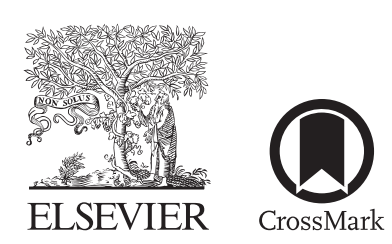

\title{
Sex Differences in Abdominal Aortic Aneurysm: The Role of Sex Hormones
}

\author{
Georgios Makrygiannis, ${ }^{1}$ Audrey Courtois, ${ }^{1,2}$ Pierre Drion, ${ }^{3}$ Jean-Olivier Defraigne, ${ }^{4}$ \\ Helena Kuivaniemi, ${ }^{5,6}$ and Natzi Sakalihasan, ${ }^{1,4}$ Liège, Belgium; and Danville, Pennsylvania
}

\begin{abstract}
Abdominal aortic aneurysm (AAA) is a complex multifactorial disease with genetic and environmental components. AAA is more common in men, whereas women have a greater risk of rupture and more frequently have concomitant thoracic aortic aneurysms. Moreover, women are diagnosed with AAA about 10 years later and seem to be protected by female sex hormones. In this MEDLINE-based review of literature, we examined human and animal in vivo and in vitro studies to further deepen our understanding of the sexual dimorphism of AAA. We focus on the role of sex hormones during the formation and growth of AAA. Endogenous estrogens and exogenous $17 \beta$-estradiol were found to exert favorable actions protecting from AAA in animal models, whereas exogenous hormone replacement therapy in humans had inconclusive results. Androgens, known to have detrimental effects in the vasculature, in sufficient levels maintain the integrity of the aortic wall through their anabolic actions and act differentially in men and women, whereas lower levels of testosterone have been associated with AAA in humans. In conclusion, sex differences remain an important area of AAA research, but further studies especially in humans are needed. Furthermore, differential molecular mechanisms of sex hormones constitute a potential therapeutic target for AAA.
\end{abstract}

Conflicts of Interest: G.M. was funded by the Aneurysmal Pathology Foundation (APF).

Conflict of interest None.

${ }^{1}$ Department of Cardiovascular Surgery, Surgical Research Center, GIGA-Cardiovascular Unit, University Hospital of Liège, Liège, Belgium.

${ }^{2}$ Laboratory of Connective Tissue Biology, GIGA-Cardiovascular Unit, University of Liège, Liège, Belgium.

${ }^{3}$ Surgical Research Center, GIGA-Cardiovascular Unit, University Hospital of Liège, Liège, Belgium.

${ }^{4}$ Department of Cardiovascular Surgery, University Hospital of Liège, Liège, Belgium.

${ }^{5}$ The Sigfried and Janet Weis Center for Research, Geisinger Health System Danville, PA.

${ }^{6}$ Department of Surgery, Temple University School of Medicine, Philadelphia, PA.

Correspondence to: Georgios Makrygiannis, MD, MSc, Department of Cardiovascular Surgery, Surgical Research Center (CREDEC), GIGA-Cardiovascular Unit, University Hospital of Liege, Avenue de l'Hôpital 1, B23/+5, 4000 Liège, Belgium; E-mails: gmakrygiannis@ ulg.ac.be or g.makrygiannis@yahoo.com

Ann Vasc Surg 2014; 28: 1946-1958

http://dx.doi.org/10.1016/j.avsg.2014.07.008

(c) 2014 Elsevier Inc. All rights reserved.

Manuscript received: April 2, 2014; manuscript accepted: July 27, 2014;

published online: August 6, 2014.

\section{INTRODUCTION}

Abdominal aortic aneurysm (AAA) is a multifactorial disease with genetic and environmental components. It is characterized by inflammation of the aortic wall, modulation of the extracellular matrix (ECM), apoptosis of smooth muscle cells (SMCs), complex atherosclerosis, and oxidative stress. ${ }^{1-4}$ Microorganisms such as Chlamydia pneumoniae, Porphyromonas gingivalis, Streptococcus mutans, and Borrelia burgdorferi have been associated with the pathogenesis of AAA. 2,5

The prevalence of AAAs that are $2.9-4.9 \mathrm{~cm}$ in diameter ranges from $1.3 \%$ in men from 45 to 54 years of age to $12.5 \%$ in men from 75 to 84 years of age. For women, the prevalence ranges from $0 \%$ in the youngest to $5.2 \%$ in the oldest age. ${ }^{6}$ In addition, AAA is diagnosed about 10 years later in women than in men. ${ }^{7}$ In a recent meta-analysis, female patients under surveillance for a small AAA $(3.0-5.4 \mathrm{~cm})$ were found to have four times greater risk of rupture than men, although the growth rates of AAA were similar in both sexes. ${ }^{8}$ Moreover, for a 


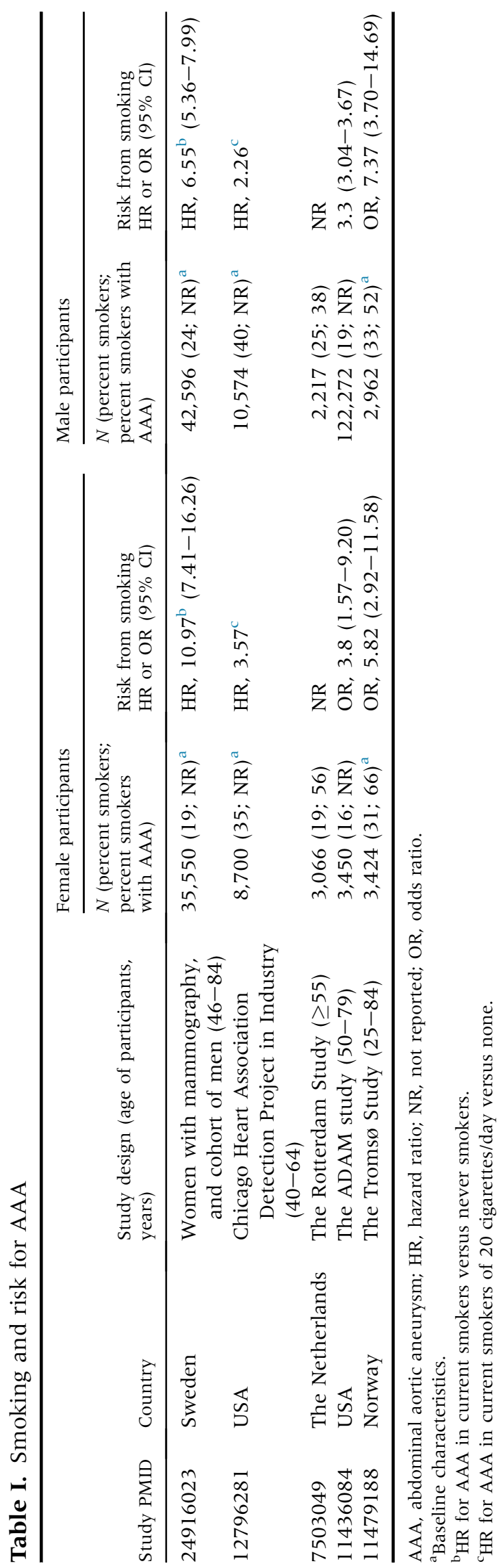

specific diameter, time until rupture is shorter in women than in men. ${ }^{9}$

The underlying mechanisms of sex differences in the prevalence and incidence as well as the natural history of AAA are not fully understood. Here, we review human and animal studies summarized in Tables I, II, and III and discuss the different hypotheses proposed about the sex differences in AAA, regarding the role of sex hormones.

\section{LITERATURE SEARCH}

Studies were identified by MEDLINE searches using different combinations of keywords "abdominal aortic aneurysm(s)," "sex differences," "gender differences," "(o)estrogens," "androgens," " $17 \beta$ estradiol," "testosterone," "sex hormones," "rodents," "metalloproteinases," "prevalence," "incidence," "natural history," "risk factors," "pathophysiology," "biomechanical properties," "elastin," and "collagen." For all genes, we use the approved gene symbols found at www.ncbi. nlm.nih.gov/gene.

\section{HUMAN AAA STUDIES}

\section{Risk Factors for AAA in Men and Women}

Male sex is one of the strongest risk factors for AAA along with advanced age, smoking, and family history, whereas hypertension and dyslipidemia have weaker associations. ${ }^{10-13}$ Smoking is the most important risk factor for $\mathrm{AAA},{ }^{14}$ and several studies have demonstrated that smoking is a stronger risk factor for AAA in women than men. We have summarized these studies in Table I. Three studies found that the hazard ratio having an AAA was higher among female than male smokers, ${ }^{11,12,15}$ l study found statistically undistinguishable odds ratio (OR) for AAA among ever-smoking men and women, ${ }^{10}$ and another study showed that the risk for AAA among current smokers was higher in men than in women. ${ }^{13}$ In conclusion, smoking appears to be a stronger risk factor for AAA in women. This is a major health problem, because the number of women who smoke continues to increase, whereas the number of male smokers is decreasing. ${ }^{16}$

Hypertension is also a risk factor with controversial results between sexes. ${ }^{14}$ Rodin et al. ${ }^{13}$ found that hypertension is a risk factor for men only, ${ }^{12}$ whereas the Tromsø Study found an opposite result. Hyperlipidemia has a weak association with AAA, and the risk for AAA was found to be similar between sexes. ${ }^{10,12,13}$ Estrogens may also influence indirectly the formation and growth of AAA, by 
Table II. Sex differences in human AAA and the influence of sex hormones in AAA

\begin{tabular}{|c|c|c|c|}
\hline Study PMID & Study design & Participants & Main findings \\
\hline 20061425 & Cross sectional & 3,620 Men, 70-88 years; 262 with AAA & $\begin{array}{l}\text { Decreased serum total and free testosterone, } \\
\text { Increased LH in AAA patients }\end{array}$ \\
\hline 18854591 & Prospective observational cohort study & 161,808 Postmenopausal women; 184 with AAA & HRT not associated with AAA \\
\hline 17512215 & Cohort study & $\begin{array}{l}\text { 104,813 Men and women; } 490 \text { men and } 115 \\
\text { women with AAA }\end{array}$ & HRT had no effect on AAA \\
\hline 16824852 & The Estrogen Alone trial & $\begin{array}{l}\text { 10,739 Postmenopausal women with prior } \\
\text { hysterectomy }\end{array}$ & $\begin{array}{l}\text { AAAs (HR, } 2.40 ; 95 \% \text { CI, } 0.92-6.23 \text { ) more } \\
\text { frequent, but not individually significant, } \\
\text { in estrogen group }\end{array}$ \\
\hline 14769684 & The Estrogen Plus Progestin trial & 16,608 Postmenopausal women & No difference in AAA prevalence \\
\hline 21119710 & $\begin{array}{l}\text { Genetic association, } 74 \text { SNPs in } 4 \text { genes } \\
\text { (SRD5A1,CYP19A1,AR, ESR2) related } \\
\text { to sex hormones }\end{array}$ & $\begin{array}{l}\text { 1,711 Men, } 640 \text { with AAA. One genotype } \\
\text { assessed in an independent cohort of } 782 \\
\text { men, } 513 \text { with large AAAs }\end{array}$ & $\begin{array}{l}\text { SNP in CYP19A1 associated with aortic } \\
\text { diameter but not in the cohort of large } \\
\text { AAAs }\end{array}$ \\
\hline 15698546 & $\begin{array}{l}\text { Genetic association: SNPs in ELN, ESR1, } \\
\text { ESR2, } P R \text { and TGFB1 }\end{array}$ & 99 AAA and 225 controls (all men) & ESR2-AluI associated with AAA \\
\hline 22721599 & $\begin{array}{l}\text { Prospective case-control study; plasma } \\
\text { MMP2, 9, and 13, TIMP1, SERPINE1, } \\
\text { hSCRP; and estradiol by ELISA }\end{array}$ & $\begin{array}{l}16 \text { Women and } 18 \text { men with AAAs } \geq 5.5 \mathrm{~cm} \text {, } \\
20 \text { women with } \\
\text { AAAs }<5.5 \mathrm{~cm} ; 18 \text { women with PAD }\end{array}$ & $\begin{array}{l}\text { Women with AAAs: Increased MMP9 } \\
\text { and decreased estradiol compared with } \\
\text { men. Women with AAAs: Decreased } \\
\text { MMP9 compared without AAA. }\end{array}$ \\
\hline 23993200 & $\begin{array}{l}\text { Expression study on AAA tissue, Western } \\
\text { blot }\end{array}$ & 6 Operated AAAs and 4 cadavers & ESRl protein: $\mathrm{F}>\mathrm{M}$ \\
\hline 24582702 & Human AAA tissue, immunohistochemistry & NR & $\begin{array}{l}\text { AAA SMCs and macrophages express } \\
\text { aromatase }\end{array}$ \\
\hline 24332015 & Expression study on AAA tissue & 12 Men and 6 women & Differential AKT phosphorylation \\
\hline 23395130 & $\begin{array}{l}\text { Biomechanical analysis of ILT and aortic } \\
\text { wall }\end{array}$ & 90 AAA samples: 78 men and 12 women & $\begin{array}{l}\text { Women: older AAA thrombi, aortic wall } \\
\text { more prone to dissection, more elastin } \\
\text { and less collagen }\end{array}$ \\
\hline 11532424 & Measure the area ratio of ILT in CT images & 98 AAA patients & Women: correlated with small ILT \\
\hline 17182963 & $\begin{array}{l}\text { Measure uniaxial tensile stress of AAA } \\
\text { tissues }\end{array}$ & 76 AAA tissues from 34 patients $(24 \mathrm{M}, 10 \mathrm{~F})$ & $\begin{array}{l}\text { A trend in strength of the aortic wall: } \\
\mathrm{F}<\mathrm{M}\end{array}$ \\
\hline 21397436 & FEA of PWS, PWRR & 15 Men and 15 women (AAA: $4-6 \mathrm{~cm}$ ) & PWRR slightly increased in women \\
\hline
\end{tabular}

AAA, abdominal aortic aneurysm; AR, androgen receptor; CI, confidence interval; CT, computed tomography; CYP19Al, cytochrome P450, family 19, subfamily A, polypeptide 1; ELN, elastin; ESR1, estrogen receptor 1; ESR2, estrogen receptor 2; F, females; FEA, finite element analysis; HR, hazard ratio; HRT, hormone replacement therapy; hsCRP, high-sensitivity Creactive protein; ILT, intraluminal thrombus; LH, luteinizing hormone; M, males; NR, not reported; PR, progesterone receptor; PWRR, peak wall rupture risk; PWS, peak wall stress; SNP, single nucleotide polymorphism; SRD5Al, steroid-5-alpha-reductase, alpha polypeptide 1; TGFB1, transforming growth factor, beta 1.

The studies are listed with their PubMed IDs. A detailed list of the literature citations is available from the authors. 
Table III. Animal model studies examining sex differences in AAA

\begin{tabular}{|c|c|c|c|}
\hline Study PMID & Animal species & Drug and/or operation & Main findings \\
\hline \multicolumn{4}{|c|}{ Elastase model } \\
\hline 11557662 & $\begin{array}{l}\text { Mice M/F } \\
\quad \text { C57BL/6J, Nos2 } 2^{-/-}\end{array}$ & Oophorectomy & $\operatorname{Nos} 2^{-1-}$ : AAA inc. $\mathrm{F}<\mathrm{M} ; \mathrm{F} N o s 2^{-/-}$increased AAA inc. and miAD than fC \\
\hline 15331435 & $\begin{array}{l}\text { Rats } M / F \\
\quad \text { Sprague-Dawley }\end{array}$ & $\begin{array}{l}17 \beta \text {-estradiol/aortic } \\
\text { transplantation }\end{array}$ & $\begin{array}{l}\mathrm{M}>\mathrm{F} \text { AAA inc., miAD, macrophages, and } M M P 9 \text {; lost AAA resistance } \\
\text { after } \mathrm{F} \text { to } \mathrm{M} \text { aortic transplantation }\end{array}$ \\
\hline 15696052 & $\begin{array}{l}\text { Rats } M \\
\quad \text { Sprague-Dawley }\end{array}$ & Tamoxifen & $\begin{array}{l}\text { mTam decreased AAA diameter, neutrophils, MMP9, increased catalase } \\
\text { than mS. }\end{array}$ \\
\hline 17182958 & $\begin{array}{l}\text { Rats M/F } \\
\quad \text { Sprague-Dawley }\end{array}$ & & $\begin{array}{l}\text { M > F AAA inc., miAD, macrophages, neutrophils, many cytokine and } \\
\text { chemokine families }\end{array}$ \\
\hline 19111327 & $\begin{array}{l}\text { Rats } M / F \\
\quad \text { Sprague-Dawley }\end{array}$ & $\begin{array}{l}\text { 17ß-estradiol, } \\
\text { testosterone/ } \\
\text { oophorectomy, } \\
\text { orchiectomy }\end{array}$ & $\begin{array}{l}\text { mE2 and } \mathrm{mC} \text { decreased AAA miAD, and macrophages than mS; mCT } \\
\text { increased } \mathrm{AD} \text { than mCTS; fCE2 decreased miAD and macrophages } \\
\text { than fCE } 2 \mathrm{~S}\end{array}$ \\
\hline 18585678 & $\begin{array}{l}\text { Rats } M / F \\
\text { Wistar }\end{array}$ & $\begin{array}{l}\text { 17 } \beta \text {-estradiol/ } \\
\text { ovariectomy }\end{array}$ & $\begin{array}{l}\text { mE2 decreased AAA miAD, MMP2, and MMP9 than mS; fC increased } \\
\text { AAA miAD, MMP2, and MMP9 than fS }\end{array}$ \\
\hline 19767051 & $\begin{array}{l}\text { Rats M/F } \\
\quad \text { Sprague-Dawley }\end{array}$ & & $\begin{array}{l}\text { M increased AAA inc., miAD, macrophages, neutrophils, Tgfbl, MMP13, } \\
\text { collagen type I and III, and total collagen than F }\end{array}$ \\
\hline 22316675 & $\begin{array}{l}\text { Mice } \mathrm{M} / \mathrm{F} \\
\mathrm{C} 57 / \mathrm{B} 6\end{array}$ & & $\begin{array}{l}\text { M increased AAA inc., miAD, macrophages, proMMP9, pro-MMP2, MMP2, } \\
\text { and Mapk8 than F }\end{array}$ \\
\hline 22307671 & $\begin{array}{l}\text { Mice M/F } \\
\quad \text { C57BL/6, Serpine1 } 1^{-1-}\end{array}$ & & $\begin{array}{l}\text { M increased AAA inc. }(w t), \text { miAD }(w t), \text { macrophages (wt and Serpine }{ }^{-/-} \text {), } \\
\text { pro-MMP2, pro-MMP9, MMP2 (wt) and decreased } \\
\text { Serpinel than F }\end{array}$ \\
\hline 23993200 & $\begin{array}{l}\text { Mice M/F } \\
\quad \text { C57 }\end{array}$ & & M increased AAA miAD, MMP2, MMP9, and decreased Esrl than F \\
\hline 24388399 & Mice M/F C57BL/6 & Phytoestrogens & Phytoestrogens inhibited AAA in M mice \\
\hline 24582702 & $\begin{array}{l}\text { Mice C57BL/6 M/F, wt, } \\
\text { ArKO }\end{array}$ & ovariectomy & $\begin{array}{l}\text { Expression of aromatase in AAA SMCs and macrophages, important } \\
\text { peripheral synthesis of estrogen }\end{array}$ \\
\hline 24332015 & Mice M/F C57BL/6 & & Differential AKT phosphorylation between sexes \\
\hline \multicolumn{4}{|c|}{ Angiotensin II model } \\
\hline 12083734 & $\begin{array}{l}\text { Mice M/F } \\
\text { C57BL/6 } \text { Apoe }^{-/-} / \mathrm{Ldlr}^{-1-}\end{array}$ & & AAA inc.: $\mathrm{M}>\mathrm{F}$ \\
\hline 12855485 & $\begin{array}{l}\text { Mice M } \\
\text { Apoe }^{-/-}\end{array}$ & $17 \beta$-estradiol & $\begin{array}{l}\text { mE2 decreased AAA inc., miAD, Icaml, Vcaml, Sele, CCL2, Csfl gene } \\
\text { expression, increased Ppara, Ppard than mS, 17 } \beta \text {-estradiol reversed } \\
\text { the effects of AngII on transcriptional factors. }\end{array}$ \\
\hline 15105380 & $\begin{array}{l}\text { Mice M/F } \\
\text { C57BL/6J } \\
\text { Apoe }^{-1-}\end{array}$ & $\begin{array}{l}\text { Ovariectomy, } \\
\text { orchiectomy }\end{array}$ & mC decreased AAA inc. than $\mathrm{mS}$ \\
\hline & & & (Continued) \\
\hline
\end{tabular}


Table III. Continued

\begin{tabular}{|c|c|c|c|}
\hline Study PMID & Animal species & Drug and/or operation & Main findings \\
\hline 18451329 & $\begin{array}{l}\text { Mice M/F } \\
\text { C57BL/6 } \\
\text { Apoe }^{-1-}\end{array}$ & $\begin{array}{l}\text { DHT/ovariectomy, } \\
\text { orchiectomy }\end{array}$ & mCDht increased AAA inc. than $\mathrm{mC}$; fCDht increased AAA inc. than fC \\
\hline 22539767 & $\begin{array}{l}\text { Mice M/F } \\
\text { C57BL/6 Apoe } e^{-/-}-L_{d l r^{-/-}} \\
\text {Agtrla } \alpha^{\text {flox/flox }}, \text { Agtrla } a^{\mathrm{SM} 22} \mathrm{KO}\end{array}$ & Testosterone & $\begin{array}{l}\text { Neonatal testosterone: increased AAA inc. in adult } \mathrm{F} \text { mice but no effect in } \\
\text { adult } \mathrm{M} \text { mice }\end{array}$ \\
\hline 24439319 & $\begin{array}{l}\text { Mice M } \\
\text { Apoe }^{-1-}\end{array}$ & orchiectomy & Removal of endogenous male hormones attenuates aortic lumen expansion \\
\hline \multicolumn{4}{|c|}{ Topical elastase } \\
\hline 22651981 & $\begin{array}{l}\text { Mice M/F } \\
\text { C57BL/6 and B6129 }\end{array}$ & & C57BL/6: macrophages: $\mathrm{M}>\mathrm{F}$ \\
\hline \multicolumn{4}{|c|}{ Cultured rat aortic SMCs, stimulated with IL1B } \\
\hline 16125073 & $\begin{array}{l}\text { Rats } \mathrm{M} / \mathrm{F} \\
\quad \text { Sprague-Dawley }\end{array}$ & $17 \beta$-estradiol & MMP9 and Timpl: $M>$ F, not altered by $17 \beta$-estradiol \\
\hline 19041098 & $\begin{array}{l}\text { Rats M/F } \\
\quad \text { Sprague-Dawley }\end{array}$ & $17 \beta$-estradiol & MMP2, MMP2/Timp2: M > F; not altered by $17 \beta$-estradiol \\
\hline 19592018 & Rats M/F; Sprague-Dawley & & p-Mapkl, t-Mapkl, and pro-MMP2: M > F \\
\hline
\end{tabular}

ArKO, without aromatase; Agt (AngII), Angiotensin II; Agtrla, angiotensin II receptor, type la; Apoe, apolipoprotein E; CXL2, chemokine (C-C motif) ligand 2; Csf, colony-stimulating factor 1 (macrophage); Esrl, estrogen receptor 1; F, females; fC, castrated females; fCDht, castrated females treated with dihydrotestosterone; fCE2, castrated females treated with 17ßestradiol; fCE2S, castrated control females; fS, sham females; Icaml, intercellular adhesion molecule 1; inc., incidence; KO, knockout; Ldlr, low-density lipoprotein receptor; M, males; Mapk8, mitogen-activated protein kinase 8 (Jnkl); mC, castrated males; mCDht, castrated males treated with dihydrotestosterone; mCT, castrated males treated with testosterone; mCTS, castrated control males; mE2, males treated with 17-ßestradiol; miAD, mean increase of the aortic diameter; MMP2, matrix metalloproteinase 2; MMP9, matrix metalloproteinase 9; MMP13, matrix metalloproteinase 13; mS, sham males; mTam, males treated with tamoxifen; Nos2, nitric oxide synthase 2, inducible; p-Mapk1, phosphorylated mitogen-activated protein kinase 1 (p-Erk); Ppara, peroxisome proliferator activated receptor alpha; Ppard, peroxisome proliferator activator receptor delta; Sele, selectin, endothelial cell; Tgfbl, transforming growth factor, beta 1; Timpl, tissue inhibitor of metalloproteinase 1; Timp2, tissue inhibitor of metalloproteinase 2; t-Mapk1, t-mitogen-activated protein kinase 1 (t-Erk); Vcaml, vascular cell adhesion molecule l; wt, wild type.

The studies are listed with their PubMed IDs. A detailed list of the literature citations is available from the authors. 
elevating high-density lipoprotein (HDL) and reducing low-density lipoprotein (LDL) ${ }^{17}$ Diabetes is known to be inversely correlated with $\mathrm{AAA}^{18}$ and in some studies, its protective effect is more prominent in women than in men, ${ }^{11}$ although other studies did not find any difference between the sexes. ${ }^{10}$ Finally, women with AAA have greater comorbidity of cerebrovascular disease ${ }^{10}$ and thoracic aortic aneurysms ${ }^{19}$ than men.

Many studies have demonstrated that family history is an important risk factor for the development of AAAs (for a summary of all published studies, see Sakalihasan et al. ${ }^{20}$ ). In a recent study from our Cardiovascular Surgery Center, ultrasonography screening of relatives of 144 AAA patients identified 24 new AAAs among 186 relatives ( $\geq 50$ years) yielding a prevalence of $13 \%$. The highest prevalence $(25 \%)$ was found among brothers. By combining the number of AAAs found by ultrasonography screening with those diagnosed previously, the observed lifetime prevalence of AAA was estimated to be $32 \%$ in brothers. ${ }^{20}$ Although previous studies had suggested that women with AAA are more likely to have a family history of $\mathrm{AAA}^{21}$ our study of 618 Belgian AAA patients did not find a difference in the sex distribution between the sporadic $(n=539)$ and familial $(n=79)$ AAA cases with male AAA patients representing $92 \%$ of the AAA patients in both groups. ${ }^{20}$ A populationbased study in Sweden using national registries found that the relative risk of AAA for the firstdegree relatives of both male and female AAA patients was similar. ${ }^{22}$

\section{Role of Sex Hormones in AAA Development and Growth}

Clinical studies in men. In a cross-sectional study of Australian men, the AAA patients had lower free and total testosterone and higher luteinizing hormone levels than men without AAA. In addition, the levels of free testosterone were inversely correlated with AAA (Table II). ${ }^{23}$ Lower testosterone level has been also linked with coronary artery disease, ${ }^{24}$ lower extremity peripheral arterial disease, ${ }^{25}$ and increased inflammation in human endothelial cells. ${ }^{26}$ Indeed, testosterone has beneficial actions on the muscle mass, endothelium, circulating lipids, and vascular inflammation and through its anabolic actions could maintain the integrity of vascular SMCs and ECM, thus compensating the aortic medial degradation found in AAA. ${ }^{23}$

Genetic studies in men. In "Health In Men Study," 74 single-nucleotide polymorphisms (SNPs) located in 4 genes encoding circulating sex hormones (steroid 5 alpha reductase, subfamily A, polypeptide 1 [SRD5A1], cytochrome P450, family 19 , subfamily A, polypeptide l [CYP19A1], androgen receptor $[A R]$, and estrogen receptor 2 [ESR2]) were analyzed. As genetic factors appear to have a role in the production, metabolism, and response to male sex hormones, an association was found between small AAAs and 1 SNP located in intron 1 of CYP19A1, but this finding was not confirmed in an independent cohort of large aneurysms. ${ }^{27}$

As receptors of female sex hormones mediate their effects in vascular SMCs and in endothelial cells, genes encoding for these receptors provide biologically plausible candidate genes for genetic studies. A small study with 99 AAA cases and 225 controls revealed a polymorphism in the estrogen receptor $\beta$ (ESR2) but not estrogen receptor $\alpha$ $(E S R 1)$, elastin $(E L N)$, progesterone receptor $(P R)$, or transforming growth factor $\beta 1$ (TGFBI) genes to be associated with AAA. ${ }^{28}$ Larger studies are needed to draw firm conclusions about the role of genetic variation in these genes.

Clinical studies in women. In a prospective observational cohort study, hormone replacement therapy (HRT) of $>5$ years decreased the OR for AAA to $0.52(0.34-0.78),{ }^{29}$ whereas another study showed no effect. ${ }^{30}$ Moreover, in the "Estrogen Plus Progestin Trial," there was no difference in the number of AAA cases between the women receiving estrogen plus progestin and the control group. ${ }^{31}$ However, in the "Estrogen Alone Trial," a study on postmenopausal women with prior hysterectomy, AAA events were more frequent in the group receiving conjugated equine estrogen than the control group. ${ }^{32}$ This divergence on the results may be attributed to different duration of treatment as well with differences in women's lifestyles. The earlier after menopause the HRT starts, the better vascular effect the estrogens have, indicating that time of treatment onset since menopause is key in cardiovascular protection. ${ }^{33}$ On the other hand, HRT can trigger adverse thrombotic and proinflammatory outcomes. ${ }^{33}$ The vasoprotective effects of $17 \beta$-estradiol are age dependent and may also explain the vasotoxic effect of estrogen observed in a clinical trial of postmenopausal women. ${ }^{34}$ Finally, a case-control study using validated questionnaires showed that women with AAA $\geq 5 \mathrm{~cm}$ had menopause at a younger age than women with $\mathrm{AAA}<5 \mathrm{~cm}$, without relationship to HRT, suggesting that a shorter period of sex hormone production, as a consequence of lower menopausal age, is related to an earlier development of AAA or increased growth rate. ${ }^{35}$

Protein expression in women and men in AAA. As for protein studies, a small case-control study (16 
women and 18 men with AAAs $\geq 5.5 \mathrm{~cm}$ and 20 women with AAA $<5.5 \mathrm{~cm}$ ) found higher plasma levels of matrix metalloproteinase 9 (MMP9) in women compared with men with equivalent large AAAs, suggesting a sex difference in proteolytic activity of the aortic wall, whereas the levels of estradiol were lower in women compared with those in men. In elderly men, higher levels of estradiol can be explained by peripheral aromatization and continued synthesis in the testicles. ${ }^{36}$ Interestingly, women with AAAs $>5.5 \mathrm{~cm}$ had lower levels of MMP9 compared with women with AAA $<5.5 \mathrm{~cm}$, which could be explained either by MMP9 degradation in the aneurysmal wall or a reduction in the MMP9 production as the aneurysm grows. ${ }^{36}$ Laser et al. ${ }^{37}$ found that ESR 1 protein levels were $80 \%$ higher in the aortic wall of women than in men with AAA. Furthermore, aromatase, an essential enzyme of estrogen synthesis, was expressed in aortic cells expressing smooth muscle markers $(\mathrm{SM} \alpha \mathrm{A})$ and macrophage markers (CD68 and Mac2 ) in human AAA tissues. ${ }^{38}$ Finally, aortas from men with AAA $(n=12)$ had a significantly higher phosphorylated AKT-308 (p308)/total AKT ratio than tissues from women with AAA $(n=6)$, suggesting that phosphorylation of AKT, which is a serine/ threonine kinase, is important in the upstream regulation of MMP activity and that differential phosphorylation contributes to sex differences in AAA. ${ }^{39}$

Clinical conclusion from human sex hormone studies on $\boldsymbol{A A A}$. There is a lack of human studies examining the role of androgens in AAA. As AAA is associated with an advanced age, age-related decline in circulating testosterone could be a contributing factor, but further studies are required to establish this connection. Estrogens mediate beneficial anti-inflammatory effects by direct antioxidant effect, generation of nitric oxide, prevention of apoptosis, and suppression of cytokines and chemokines, but there are scarce human studies examining the role of endogenous estrogen on AAA. Furthermore, several human studies documented contradictory results on the role of exogenous female sex hormones on AAA.

\section{ANATOMIC AND BIOMECHANICAL PROPERTIES OF MALE AND FEMALE AAA PATIENTS}

In 1965, Steinberg et al. ${ }^{40}$ established normal standards for abdominal aortic diameters. In men, the mean diameter of the suprarenal aorta was $19.3 \mathrm{~mm}$, and the infrarenal diameter was $18.1 \mathrm{~mm}$ with an infrarenal/suprarenal ratio 0.94.
In women, the mean diameter of the aorta was smaller than men: suprarenal $17.9 \mathrm{~mm}$, infrarenal $15.8 \mathrm{~mm}$, and infrarenal/suprarenal ratio 0.86 . Moreover, a Scandinavian study reported a 3-mm sex difference in aortic diameter in 70-year-old subjects, ${ }^{41}$ whereas in the ADAM study, the aortic diameter was approximately $1.4 \mathrm{~mm}$ smaller in women than in men. ${ }^{42}$ Furthermore, because aortic size is proportional to the body size, a 5.5$\mathrm{cm}$ AAA in men is similar to a $5.2-\mathrm{cm}$ AAA in women, and AAAs with equal diameter represent a greater proportional dilatation in women than in men. ${ }^{43}$ Likewise, when measuring the uniaxial tensile stress, women were found to have lower wall strength compared with men. ${ }^{44}$ In addition, women present with overall more diseased aortic neck, such as shorter aortic neck, wider proximal aortic neck, and more frequent proximal angulation $>60^{\circ} .{ }^{45}$

Variation in sex hormone levels between men and women in every age group influences expression of important ECM proteins and may modulate arterial stiffness. ${ }^{46}$ Although the ECM in human aorta is complex, it is clear that the collagens primarily convey strength, whereas elastin and related proteins including fibrillin 1 convey distensibility. ${ }^{46}$ In a study on human aortic SMCs, all exogenous sex steroids reduced collagen deposition compared with control; however, the reduction was greater with female sex steroids than testosterone. ${ }^{46}$ Furthermore, the elastin/collagen ratio was 11 -fold higher, and fibrillin 1 deposition was doubled in the presence of $17 \beta$-estradiol and progesterone compared with that of testosterone, whereas testosterone increased both gene and protein expression of MMP3 compared either to untreated cells or cells treated with female sex steroids. Besides, in a study on postmenopausal women, phytoestrogen treatment decreased the aortic stiffness, ${ }^{47}$ whereas smoking induced greater stiffening of aortic wall in women than in men, indicating that the aorta of women might be more vulnerable to smoking with regard to stiffening and degenerative changes than the aorta of men. ${ }^{48}$ Male AAA patients had less dry weight percentage of elastin and more collagen than female patients in the abdominal aortic wall. ${ }^{49}$ As the amount of collagen increases, the cross linking between collagen fibers increases resulting in greater stiffening. ${ }^{49}$ In addition, a decreased distensibility of the vessel happens earlier in men, who are more susceptible to developing AAA,${ }^{50}$ whereas the compensatory increase of the aortic wall is greater in women than in men to reduce the circumferential stress in the aorta. ${ }^{51}$ In every age group, women have less stiff aortas than 
men, and this is largely influenced by their smaller body size and arterial dimensions. ${ }^{52,53}$ Furthermore, sex differences in the stiffness of the aorta may be associated with slightly lower mean arterial pressure in women ${ }^{43}$ and with degenerative changes related to aging, contributing to the formation of AAA. ${ }^{52}$

The risk of rupture is a cumulative effect of abdominal aortic geometry, intraluminal thrombus (ILT) characteristics, tissue properties, and blood pressure. $^{54}$ Tong et al. ${ }^{49}$ found that the luminal layers of ILT in women were more biaxially extensible but weaker in longitudinal direction, whereas the abluminal layers had no differences between sexes. Another study showed that women with AAA had smaller ILT compared with men, but this does not explain the higher risk of rupture in women, ${ }^{55}$ because AAA wall adjacent to thicker ILT is weaker and exposed to hypoxia compared with the AAA wall adjacent to a thinner layer of ILT. ${ }^{54}$ Finally, in a study using finite element analysis, women had higher peak wall rupture risk. ${ }^{54}$

\section{SEX DIFFERENCES IN AAA ANIMAL MODELS}

\section{The Role of Endogenous Sex Hormones}

In 1970s, before the AAA experimental models, Fischer et al. ${ }^{56}$ found that rats receiving estradiol had a higher aortic elastin/collagen ratio than those receiving testosterone. More recently, sex differences in AAA have been studied in different animal models, which include the intraluminal infusion of elastase in rats ${ }^{57}$ or mice, ${ }^{58}$ angiotensin II (AngII) infusion in mice deficient in apolipoprotein $\mathrm{E}$ $\left(\right.$ Apo $\left.^{-1-}\right),{ }^{59}$ and direct application of elastase at the anterior wall of the abdominal aorta in mice (Table III). ${ }^{60}$

In 2001, Lee et al. ${ }^{61}$ described an increased incidence of AAA in female mice deficient in the inducible form of nitric oxide synthase $\left(\mathrm{Nos}^{-/-}\right)$ compared with male mice ( $80 \%$ vs. $40 \%$ ), suggesting that the interaction between estrogen and cellular NOS could influence nitric oxide production and that the absence of NOS2 might have enhanced local MMP9 activity and promoted aneurysmal degeneration in a sex-specific manner. Another study reported a higher incidence and a larger size of AAA in male than in female mice in Apoe $^{-1-}$ and in low-density lipoprotein receptor $\left(\mathrm{Ldlr}^{-/-}\right)-$ deficient mice in the AngII AAA model, ${ }^{62}$ as it is known that androgens increase the expression of the renin-angiotensin system components, including angiotensinogen, renin, and angiotensin
II receptor type-1 receptors (AGTR 1 ). ${ }^{63}$ Using the elastase perfusion model, Ailawadi et al. similarly found higher incidence and an increase in abdominal aortic diameter in male compared with that in female rat abdominal aortas. This apparent female protection was mediated by inhibitory effect of estradiol on the aortic wall macrophage infiltration and secretion of MMP9. ${ }^{64}$ They also noticed that estrogen-related resistant phenotype was lost after transplantation of the female aorta into male rats. Moreover, the male and female aortas had nearly identical aortic structure before any intervention, suggesting a postinjury action of estrogen. Sinha et al. ${ }^{65}$ focused on the first week after elastase perfusion, and the protective effects of female rats were associated with a decrease of macrophage and neutrophil infiltration and lower levels of multiple members of bone morphogenetic protein, $\mathrm{C}-\mathrm{C}$ chemokine ligand, C-C chemokine receptor, interleukin (IL), transforming growth factor (TGF), tumor necrosis factor (TNF), and vascular endothelial growth factor (VEGF) families in the early stages of AAA formation. Furthermore, Cho et al. ${ }^{66}$ investigated sex-related changes of ECM proteins and found that sex disparities were associated with lower levels of types I and III collagen, Tgfbl, and higher leukocyte infiltration and MMP13 levels in male rats.

DiMusto et al. ${ }^{67}$ examined sex differences in the c-Jun-N-terminal kinase (Jnk) production, an intracellular signaling molecule with important upstream regulation of several enzymes in AAA formation, inflammation, and cellular death, and found that significantly more Jnkl or mitogenactivated protein kinase $8(\mathrm{Mapk} 8)$ resulting in increase of pro- and active-MMP2 as well as proMMP9 in male versus female mice. In another study, the same group examined the role of plasminogen activator inhibitor 1 now known as Serpinel in Serpine $1^{-1-}$ mice and found that overexpression of Serpinel prevented AAA development in female compared with male mice. ${ }^{68}$ Increased levels of Serpinel decrease MMPs by reducing plasmin in the blood and can modulate plasminogen-mediated apoptosis of vascular SMCs. ${ }^{68}$ Laser et al. ${ }^{37}$ showed an increase of aortic wall Esrl in female compared with male mice aortas, which was inversely correlated with MMP activity, suggesting a protective role of Esrl during AAA formation likely because of a decreased inflammation. Another study concluded that genetic susceptibility is important in AAA development, as significantly more macrophages were found in C57BL/6 male than female mice, but there was no difference between sexes in $B 6129$ mice. $^{60}$ 
Moreover, similar to human AAA tissue, male mice had higher levels of $p 308$ which was correlated with increased AAA formation compared with female mice. ${ }^{39}$ Finally, Johnston et al. ${ }^{38}$ showed that the protective effects in female mice were completely eliminated with deletion of aromatase. Decreasing estradiol levels were correlated with increasing aortic diameter.

\section{Exogenous Estrogens in AAA}

The vasoprotective effect of exogenous estrogens is well described in animal models of AAA. Male rats treated with $17 \beta$-estradiol had smaller aortic diameter, less macrophage infiltration, and elastin fragmentation as well as lower levels of MMP9 mRNA compared with the sham group. ${ }^{64}$ The protective effects of estrogens were confirmed by other studies. ${ }^{69,70}$ Additionally, Martin-McNultry et al. ${ }^{71}$ demonstrated that infusion of AngII induced AAA in $90 \%$ of $\mathrm{Apoe}^{-/-}$mice, whereas with $17 \beta$-estradiol treatment, only $42 \%$ of mice developed AAAs. In another AAA study, tamoxifen, a selective estrogen receptor modulator, decreased neutrophil infiltration and increased catalase expression. ${ }^{72}$ Catalase is an antioxidative enzyme involved on hydrogen peroxide metabolism and can block the activation of MMP2 in SMCs. ${ }^{72}$ Finally, dietary phytoestrogens inhibited experimental AAA formation in male mice through a reduction of the inflammatory response in the aortic wall. ${ }^{73}$

\section{The Role of Exogenous Testosterone in AAA Development}

Female and male rats treated with testosterone displayed similar increase of aortic diameter and macrophage infiltration, although $30 \%$ of AAAs ruptured early in the male testosterone group. ${ }^{69}$ Zhang et al. ${ }^{74}$ found that the mRNA levels of angiotensin II receptor subtype la (Agtrla) were increased in abdominal but not in thoracic aortas, and as a consequence, the incidence of AngII-induced AAAs was increased in adult female mice but not in adult male mice administered testosterone as neonates. In SMCs cultured from abdominal aortas of female mice, but not from male mice, testosterone promotion of Agtrla was heritable, and the authors proposed that epigenetic mechanisms contribute to sexual dimorphism seen in the effects of testosterone. This study showed that long-lasting effects that persisted into adulthood did not require continued presence of high concentrations of testosterone in serum.

\section{The Effect of Castration on AAA Parameters}

Conflicting results have been obtained in studies focused on rodent female castration and its effects on AAA formation. Oophorectomized Nos2 ${ }^{-1-}$ female mice showed a decreased incidence and diameter of AAA compared with noncastrated Nos $2^{-\prime-}$ females, suggesting that the lack of estrogen reverses the accelerated AAA development and emphasizes the close interaction between estrogen and cellular NOS. ${ }^{61}$ Another study did not find a difference in the aneurysm size or the number of macrophages between ovariectomized female rats and the control group, suggesting that persistent circulating estrogen or estrogen receptors can provide continued protection against AAA formation. In addition, they demonstrated that exogenous estrogens have prominent protective effects, as castrated females treated with $17 \beta$-estradiol presented smaller AAAs and lower macrophage counts compared to only castrated females. ${ }^{69} \mathrm{Wu}$ et al. ${ }^{70}$ found SMCs disorganization, inflammatory cell infiltration, partial elastic fiber degradation, larger aneurysm size, and increased MMP2 and MMP9 mRNA levels in ovariectomized female rats, illustrating also the anti-inflammatory/antiproteolytic effects of estrogen in the elastase-induced AAA model. On the other hand, Henriques et al. ${ }^{75}$ showed that murine ovariectomy failed to significantly modify neither the incidence nor the severity of the AngII-induced AAAs, indicating that the endogenous ovarian hormones are not the primary mediators of sex differences in AngII-induced AAA. Finally, aromatase deletion further increased aortic dilatation compared with wild-type ovariectomized females, suggesting that the protective effect of female sex on AAA requires the presence of both ovarian and extragonadal/peripheral aromatase. ${ }^{38}$

In contrast, testosterone has been shown to be a primary mediator of sex differences in AngIIinduced AAAs. The incidence of AAA was strikingly reduced in orchiectomized male mice compared with sham controls (18\% vs. $85 \%$ ) and was similar to the incidence observed in female mice $(25 \%){ }^{75}$ Castrated male mice and rats treated with dihydrotestosterone and testosterone, respectively, showed a significant increase in the incidence of AAA compared with only castrated males. ${ }^{69,76}$ Recently, a study by the same group showed that castration reduced the progressive lumen dilatation of established AAAs, suggesting that androgens also play a role in the progression of AAAs in male mice and that TGFb and Serpinel may be targets of testosterone action in the progression of AAA. ${ }^{77}$ 


\section{In Vitro Studies Using Cultured SMCs}

Woodrum et al. ${ }^{78}$ examined sex differences of MMP2 in rat aortic SMCs (RASMCs). MMP2 mRNA levels and the MMP2/Timp2 ratio as well as the protein levels and gelatinolytic activity of MMP2 were higher in male compared with those of female RASMCs. Exogenous 17 $\beta$-estradiol did not change MMP2 activity in vitro in male or female RASMCs, but in vivo pretreatment greatly decreased male aortic MMP2 production. Similar results were found in MMP9 levels in RASMCs. ${ }^{79} \mathrm{Ehl}-$ richman et al. ${ }^{80}$ focused on the mitogen-activated protein kinases (MAPKs) which are known to have a significant role in increasing MMP9 activity. Levels of phosphorylated extracellular-signalregulated kinase (Erk), also known as Mapkl, were higher in male than those in female RASMCs and were associated with higher levels of proMMP2, providing a potential explanation of sex differences. $^{81}$ Finally, male RASMCs had more phosphorylated AKT than female cells. ${ }^{39}$

\section{DISCUSSION}

Based on the studies summarized in this review, males and females with AAAs, in human and animal studies, exhibited significant epidemiological, biomechanical, and pathophysiological differences. Sex steroids likely play an important role in mediating sex differences in AAA through regulation of the ECM and the inflammation of aneurysmal wall. In addition, sex steroids influence abdominal aorta stiffness through modulation of expression of ECM proteins and their regulators.

Estrogens, mainly estradiol, exert pleiotropic actions via signaling through ESR1, ESR2, and G-protein-coupled estrogen receptor mainly on endothelial cells and SMCs. ${ }^{82}$ Studies on AAA animal models showed that female sex hormones regulate certain cytokines, chemokines, and other proteins with the majority consisting of members of MAPKs, such as AKT, JNK, ERK, and as a result, they inhibit the expression and activity of certain MMPs, especially MMP2 and MMP9, providing a protective role in aneurysm formation. Moreover, the anti-inflammatory effects of estradiol are mediated through downregulation of several nuclear factor $\kappa \mathrm{B} \quad(\mathrm{NF} \kappa \mathrm{B})$-dependent proinflammatory mediators such as intracellular adhesion molecule 1 , vascular cellular adhesion molecule 1 , selectin E, monocyte chemotactic protein 1 (Mcp-1), and macrophage colony-stimulating factor in the aorta, ${ }^{71}$ while there is evidence of reciprocal antagonism between estrogen receptors and NF- $\kappa \mathrm{B}$ activity. ${ }^{83}$ As a result, macrophage and leukocyte infiltration is decreased in the aortic wall and the subsequent production of MMPs, preventing the degradation of ECM in the aortic wall. In addition, estrogen causes a decrease in the CXC chemokine family, thus reducing early inflammatory response to endoluminal vascular injury. ${ }^{84}$ The deletion of aromatase was associated with increase in Mcp-1 and IL- $1 \beta$ provoking infiltration of inflammatory cells. $^{38}$ Estrogen mainly through ESRl activates NOS2 and endothelial NOS (NOS3) pathways, reduces the oxidative stress of AAA, decreases MMP2 and MMP9, and exerts vasodilatory effects via nitric oxide. ${ }^{61,65,82}$ Changes in gene activation of NOS3 and collagen via ESR 1 and ESR2 in the media reduce the response of blood vessels to injury. ${ }^{66}$ In addition, the antiapoptotic mechanisms of estrogens and the interaction with the fibrinolytic system through an increase of Serpinel may prevent the destruction of the aortic wall. ${ }^{68,82}$ Estrogens may also influence indirectly the formation and growth of AAA, because they elevate HDL and reduce LDL. ${ }^{17}$

Males, in animal studies, developed larger AAAs than females, more frequently associated with increased leukocyte infiltration, which was preceded by a reduction in Tgfb 1 and collagen types I and III. ${ }^{66}$ Tgfbl stimulates expression of collagen and elastin, decreases inflammation, promotes vascular SMC growth, and inhibits MMP-dependent proteolysis. ${ }^{66}$ Testosterone upregulated JNK, a protein which stimulates apoptosis signaling pathway. ${ }^{67}$ Androgens increased the incidence of AngII-induced AAA in mice and had the ability to stimulate $M M P 2$ expression. ${ }^{75}$ The effects of androgens on AAA formation include stimulation of components of the renin-angiotensin system producing either increased synthesis or responsiveness to AngII. ${ }^{75}$ Despite the many detrimental effects of testosterone, some studies revealed that androgens exert atheroprotective effects against cardiovascular disease at least in the elderly people, mediated by the androgen receptors. ${ }^{85}$ Besides, lower levels of testosterone had harmful effect on AAA and on the cardiovascular system in men. ${ }^{23}$

In conclusion, there are still many controversies and unanswered questions about the sex differences in AAA. Despite the detrimental effects of male sex hormones in experimental AAAs, it seems that lower testosterone levels in men are associated with aortic dilatation, and physiological levels of endogenous male sex hormones mediate protection on the vasculature, but further studies are required to establish more conclusive results. Endogenous estrogens exert multiple vascular actions, but the 
protection of estrogens against AAA development and the contradictory role of female sex in the risk of rupture are not clear, although there are several animal studies suggesting a protective role of estrogens. The use of exogenous female sex hormones in menopausal women was found to have contradictory results. Finally, the molecular mechanisms of sex steroids in AAA might provide potential therapeutic targets for AAA once the discrepancies in the current literature have been resolved.

\section{REFERENCES}

1. Sakalihasan N, Limet R, Defawe OD. Abdominal aortic aneurysm. Lancet 2005;365:1577-89.

2. Michel JB, Martin-Ventura JL, Egido J, et al. Novel aspects of the pathogenesis of aneurysms of the abdominal aorta in humans. Cardiovasc Res 2011;90:18-27.

3. Boddy AM, Lenk GM, Lillvis JH, et al. Basic research studies to understand aneurysm disease. Drug News Perspect 2008;21:142-8.

4. Kuivaniemi H, Platsoucas CD, Tilson MD 3rd. Aortic aneurysms: an immune disease with a strong genetic component. Circulation 2008;117:242-52.

5. Hinterseher I, Gabel G, Corvinus F, et al. Presence of Borrelia burgdorferi sensu lato antibodies in the serum of patients with abdominal aortic aneurysms. Eur J Clin Microbiol Infect Dis 2012;31:781-9.

6. Go AS, Mozaffarian D, Roger VL, et al. Heart disease and stroke statistics-2014 update: a report from the American Heart Association. Circulation 2014;129:e28-292.

7. Scott RA, Bridgewater SG, Ashton HA. Randomized clinical trial of screening for abdominal aortic aneurysm in women. Br J Surg 2002;89:283-5.

8. Sweeting MJ, Thompson SG, Brown LC, et al. Meta-analysis of individual patient data to examine factors affecting growth and rupture of small abdominal aortic aneurysms. Br J Surg 2012;99:655-65.

9. Wilson KA, Lee AJ, Lee AJ, et al. The relationship between aortic wall distensibility and rupture of infrarenal abdominal aortic aneurysm. J Vasc Surg 2003;37:112-7.

10. Lederle FA, Johnson GR, Wilson SE, et al. Abdominal aortic aneurysm in women. J Vasc Surg 2001;34:122-6.

11. Pleumeekers HJ, Hoes AW, van der Does E, et al. Aneurysms of the abdominal aorta in older adults. The Rotterdam Study. Am J Epidemiol 1995;142:1291-9.

12. Rodin MB, Daviglus ML, Wong GC, et al. Middle age cardiovascular risk factors and abdominal aortic aneurysm in older age. Hypertension 2003;42:61-8.

13. Singh K, Bonaa KH, Jacobsen BK, et al. Prevalence of and risk factors for abdominal aortic aneurysms in a population-based study: The Tromso Study. Am J Epidemiol 2001;154:236-44.

14. Norman PE, Powell JT. Abdominal aortic aneurysm: the prognosis in women is worse than in men. Circulation 2007; 1 15:2865-9.

15. Stackelberg O, Bjorck M, Larsson SC, et al. Sex differences in the association between smoking and abdominal aortic aneurysm. Br J Surg 2014;101:1230-7.

16. Powell JT, Norman PE. Abdominal aortic aneurysm events in postmenopausal women. BMJ 2008;337:a1894.
17. Guetta V, Cannon RO 3rd. Cardiovascular effects of estrogen and lipid-lowering therapies in postmenopausal women. Circulation 1996;93:1928-37.

18. Lederle FA. The strange relationship between diabetes and abdominal aortic aneurysm. Eur J Vasc Endovasc Surg 2012;43:254-6.

19. Hultgren R, Larsson E, Wahlgren CM, et al. Female and elderly abdominal aortic aneurysm patients more commonly have concurrent thoracic aortic aneurysm. Ann Vasc Surg 2012;26:918-23.

20. Sakalihasan N, Defraigne JO, Kerstenne MA, et al. Family members of patients with abdominal aortic aneurysms are at increased risk for aneurysms: analysis of 618 probands and their families from the Liege AAA Family Study. Ann Vasc Surg 2014;28:787-97.

21. Darling RC 3rd, Brewster DC, Darling RC, et al. Are familial abdominal aortic aneurysms different? J Vasc Surg 1989;10: $39-43$.

22. Larsson E, Granath F, Swedenborg J, et al. A populationbased case-control study of the familial risk of abdominal aortic aneurysm. J Vasc Surg 2009;49:47-50. discussion 1.

23. Yeap BB, Hyde Z, Norman PE, et al. Associations of total testosterone, sex hormone-binding globulin, calculated free testosterone, and luteinizing hormone with prevalence of abdominal aortic aneurysm in older men. J Clin Endocrinol Metab 2010;95:1123-30.

24. Wu FC, von Eckardstein A. Androgens and coronary artery disease. Endocr Rev 2003;24:183-217.

25. Tivesten A, Mellstrom D, Jutberger H, et al. Low serum testosterone and high serum estradiol associate with lower extremity peripheral arterial disease in elderly men. The MrOS Study in Sweden. J Am Coll Cardiol 2007;50:1070-6.

26. Norata GD, Tibolla G, Seccomandi PM, et al. Dihydrotestosterone decreases tumor necrosis factor-alpha and lipopolysaccharide-induced inflammatory response in human endothelial cells. J Clin Endocrinol Metab 2006;91: 546-54.

27. Golledge J, Biros E, Warrington N, et al. A population-based study of polymorphisms in genes related to sex hormones and abdominal aortic aneurysm. Eur J Hum Genet $2011 ; 19: 363-6$

28. Massart F, Marini F, Menegato A, et al. Allelic genes involved in artery compliance and susceptibility to sporadic abdominal aortic aneurysm. J Steroid Biochem Mol Biol 2004;92:413-8.

29. Lederle FA, Larson JC, Margolis KL, et al. Abdominal aortic aneurysm events in the women's health initiative: cohort study. BMJ 2008;337:a1724.

30. Iribarren C, Darbinian JA, Go AS, et al. Traditional and novel risk factors for clinically diagnosed abdominal aortic aneurysm: the Kaiser multiphasic health checkup cohort study. Ann Epidemiol 2007;17:669-78.

31. Hsia J, Criqui MH, Rodabough RJ, et al. Estrogen plus progestin and the risk of peripheral arterial disease: the Women's Health Initiative. Circulation 2004;109:620-6.

32. Hsia J, Criqui MH, Herrington DM, et al. Conjugated equine estrogens and peripheral arterial disease risk: the Women's Health Initiative. Am Heart J 2006;152:170-6.

33. Vitale C, Fini M, Speziale G, et al. Gender differences in the cardiovascular effects of sex hormones. Fundam Clin Pharmacol 2010;24:675-85.

34. Bowling MR, Xing D, Kapadia A, et al. Estrogen effects on vascular inflammation are age dependent: role of estrogen receptors. Arterioscler Thromb Vasc Biol 2014; 34:1477-85. 
35. Villard C, Swedenborg J, Eriksson P, et al. Reproductive history in women with abdominal aortic aneurysms. J Vasc Surg 2011;54:341-5. 5 el-2.

36. Villard C, Wagsater D, Swedenborg J, et al. Biomarkers for abdominal aortic aneurysms from a sex perspective. Gend Med 2012;9:259-266 e2.

37. Laser A, Ghosh A, Roelofs K, et al. Increased estrogen receptor alpha in experimental aortic aneurysms in females compared with males. J Surg Res 2014;186:467-74.

38. Johnston WF, Salmon M, Su G, et al. Aromatase is required for female abdominal aortic aneurysm protection. J Vasc Surg 2014. http://dx.doi.org/10.1016/j.jvs.2014.01.032. [Epub ahead of print].

39. Ghosh A, Lu G, Su G, et al. Phosphorylation of AKT and abdominal aortic aneurysm formation. Am J Pathol 2014;184:148-58.

40. Steinberg CR, Archer M, Steinberg I. Measurement of the abdominal aorta after intravenous aortography in health and arteriosclerotic peripheral vascular disease. Am J Roentgenol Radium Ther Nucl Med 1965;95:703-8.

41. Wanhainen A, Themudo R, Ahlstrom H, et al. Thoracic and abdominal aortic dimension in 70-year-old men and women-a population-based whole-body magnetic resonance imaging (MRI) study. J Vasc Surg 2008;47:504-12.

42. Lederle FA, Johnson GR, Wilson SE, et al. Relationship of age, gender, race, and body size to infrarenal aortic diameter. The Aneurysm Detection and Management (ADAM) Veterans Affairs Cooperative Study Investigators. J Vasc Surg 1997;26:595-601.

43. Forbes TL, Lawlor DK, DeRose G, et al. Gender differences in relative dilatation of abdominal aortic aneurysms. Ann Vasc Surg 2006;20:564-8.

44. Vande Geest JP, Dillavou ED, Di Martino ES, et al. Genderrelated differences in the tensile strength of abdominal aortic aneurysm. Ann N Y Acad Sci 2006;1085:400-2.

45. Hultgren R, Vishnevskaya L, Wahlgren CM. Women with abdominal aortic aneurysms have more extensive aortic neck pathology. Ann Vasc Surg 2013;27:547-52.

46. Natoli AK, Medley TL, Ahimastos AA, et al. Sex steroids modulate human aortic smooth muscle cell matrix protein deposition and matrix metalloproteinase expression. Hypertension 2005;46:1129-34.

47. van der Schouw YT, Pijpe A, Lebrun CE, et al. Higher usual dietary intake of phytoestrogens is associated with lower aortic stiffness in postmenopausal women. Arterioscler Thromb Vasc Biol 2002;22:1316-22.

48. Sonesson B, Ahlgren AR, Lazer L, et al. Does long-term smoking affect aortic stiffness more in women than in men? Clin Physiol 1997;17:439-47.

49. Tong J, Schriefl AJ, Cohnert T, et al. Gender differences in biomechanical properties, thrombus age, mass fraction and clinical factors of abdominal aortic aneurysms. Eur J Vasc Endovasc Surg 2013;45:364-72.

50. Sonesson B, Lanne T, Vernersson E, et al. Sex difference in the mechanical properties of the abdominal aorta in human beings. J Vasc Surg 1994;20:959-69.

51. Astrand H, Ryden-Ahlgren A, Sandgren T, et al. Age-related increase in wall stress of the human abdominal aorta: an in vivo study. J Vasc Surg 2005;42:926-31.

52. Sonesson B, Hansen F, Stale H, et al. Compliance and diameter in the human abdominal aorta-the influence of age and sex. Eur J Vasc Surg 1993;7:690-7.

53. Smulyan H, Asmar RG, Rudnicki A, et al. Comparative effects of aging in men and women on the properties of the arterial tree. J Am Coll Cardiol 2001;37:1374-80.
54. Larsson E, Labruto F, Gasser TC, et al. Analysis of aortic wall stress and rupture risk in patients with abdominal aortic aneurysm with a gender perspective. J Vasc Surg 201 1;54:295-9.

55. Yasuhara H, Ohara N, Nagawa H. Influence of gender on intraluminal thrombus of abdominal aortic aneurysms. Am J Surg 2001;182:89-92.

56. Fischer GM, Swain ML. Effect of sex hormones on blood pressure and vascular connective tissue in castrated and noncastrated male rats. Am J Physiol 1977;232:H617-21.

57. Anidjar S, Salzmann JL, Gentric D, et al. Elastase-induced experimental aneurysms in rats. Circulation 1990;82:973-81.

58. Pyo R, Lee JK, Shipley JM, et al. Targeted gene disruption of matrix metalloproteinase-9 (gelatinase B) suppresses development of experimental abdominal aortic aneurysms. J Clin Invest 2000;105:1641-9.

59. Daugherty A, Manning MW, Cassis LA. Angiotensin II promotes atherosclerotic lesions and aneurysms in apolipoprotein E-deficient mice. J Clin Invest 2000;105:1605-12.

60. Laser A, Lu G, Ghosh A, et al. Differential gender- and species-specific formation of aneurysms using a novel method of inducing abdominal aortic aneurysms. J Surg Res 2012;178:1038-45.

61. Lee JK, Borhani M, Ennis TL, et al. Experimental abdominal aortic aneurysms in mice lacking expression of inducible nitric oxide synthase. Arterioscler Thromb Vasc Biol 2001;21: 1393-401.

62. Manning MW, Cassi LA, Huang J, et al. Abdominal aortic aneurysms: fresh insights from a novel animal model of the disease. Vasc Med 2002;7:45-54.

63. Fischer M, Baessler A, Schunkert H. Renin angiotensin system and gender differences in the cardiovascular system. Cardiovasc Res 2002; 53:672-7.

64. Ailawadi G, Eliason JL, Roelofs KJ, et al. Gender differences in experimental aortic aneurysm formation. Arterioscler Thromb Vasc Biol 2004;24:21 16-22.

65. Sinha I, Cho BS, Roelofs KJ, et al. Female gender attenuates cytokine and chemokine expression and leukocyte recruitment in experimental rodent abdominal aortic aneurysms. Ann N Y Acad Sci 2006;1085:367-79.

66. Cho BS, Roelofs KJ, Ford JW, et al. Decreased collagen and increased matrix metalloproteinase-13 in experimental abdominal aortic aneurysms in males compared with females. Surgery 2010;147:258-67.

67. DiMusto PD, Lu G, Ghosh A, et al. Increased JNK in males compared with females in a rodent model of abdominal aortic aneurysm. J Surg Res 2012;176:687-95.

68. DiMusto PD, Lu G, Ghosh A, et al. Increased PAI-1 in females compared with males is protective for abdominal aortic aneurysm formation in a rodent model. Am J Physiol Heart Circ Physiol 2012;302:H1378-86.

69. Cho BS, Woodrum DT, Roelofs KJ, et al. Differential regulation of aortic growth in male and female rodents is associated with AAA development. J Surg Res 2009;155:330-8.

70. Wu XF, Zhang J, Paskauskas S, et al. The role of estrogen in the formation of experimental abdominal aortic aneurysm. Am J Surg 2009;197:49-54.

71. Martin-McNulty B, Tham DM, da Cunha V, et al. 17 Betaestradiol attenuates development of angiotensin II-induced aortic abdominal aneurysm in apolipoprotein E-deficient mice. Arterioscler Thromb Vasc Biol 2003;23:1627-32.

72. Grigoryants V, Hannawa KK, Pearce CG, et al. Tamoxifen up-regulates catalase production, inhibits vessel wall neutrophil infiltration, and attenuates development of experimental abdominal aortic aneurysms. J Vasc Surg 2005;41:108-14. 
73. Lu G, Su G, Zhao Y, et al. Dietary phytoestrogens inhibit experimental aneurysm formation in male mice. J Surg Res 2014;188:326-38.

74. Zhang X, Thatcher SE, Rateri DL, et al. Transient exposure of neonatal female mice to testosterone abrogates the sexual dimorphism of abdominal aortic aneurysms. Circ Res 2012;110:e73-85.

75. Henriques TA, Huang J, D'Souza SS, et al. Orchidectomy, but not ovariectomy, regulates angiotensin II-induced vascular diseases in apolipoprotein E-deficient mice. Endocrinology 2004; 145:3866-72.

76. Henriques T, Zhang X, Yiannikouris FB, et al. Androgen increases ATla receptor expression in abdominal aortas to promote angiotensin II-induced AAAs in apolipoprotein E-deficient mice. Arterioscler Thromb Vasc Biol 2008;28: $1251-6$.

77. Zhang X, Thatcher S, Wu C, et al. Castration of male mice prevents the progression of established angiotensin II-induced abdominal aortic aneurysms. J Vasc Surg 2014. In Press.

78. Woodrum DT, Ford JW, Cho BS, et al. Differential effect of 17-beta-estradiol on smooth muscle cell and aortic explant MMP2. J Surg Res 2009; 155:48-53.
79. Woodrum DT, Ford JW, Ailawadi G, et al. Gender differences in rat aortic smooth muscle cell matrix metalloproteinase-9. J Am Coll Surg 2005;201:398-404.

80. Yoshimura K, Aoki H, Ikeda Y, et al. Regression of abdominal aortic aneurysm by inhibition of c-Jun N-terminal kinase. Nat Med 2005;1 1:1330-8.

81. Ehrlichman LK, Ford JW, Roelofs KJ, et al. Genderdependent differential phosphorylation in the ERK signaling pathway is associated with increased MMP2 activity in rat aortic smooth muscle cells. J Surg Res 2010;160:18-24.

82. Knowlton AA, Lee AR. Estrogen and the cardiovascular system. Pharmacol Ther 2012;135:54-70.

83. Evans MJ, Eckert A, Lai K, et al. Reciprocal antagonism between estrogen receptor and NF-kappaB activity in vivo. Circ Res 2001;89:823-30.

84. Miller AP, Feng W, Xing D, et al. Estrogen modulates inflammatory mediator expression and neutrophil chemotaxis in injured arteries. Circulation 2004;110:1664-9.

85. Ikeda Y, Aihara K, Yoshida S, et al. Effects of androgens on cardiovascular remodeling. J Endocrinol 2012;214 $1-10$. 